\title{
Analysis of Internal Combustion Engine Performance Using Design of Experiment
}

\author{
Ismail I. HDAIB, Jehad A. YAMIN*
}

\begin{abstract}
This research paper presents a theoretical study on the effect of the blending of petro-diesel with locally made biodiesel on the engine's performance and emissions from a statistical point of view. The main purpose of this study is to study how the engine performance changes with the blending of biodiesel with ordinary diesel from the performance as well as the most influential factors point of view using statistical methods. The study was conducted at a stoichiometric air-fuel ratio, engine speed range from 1000 to $3000 \mathrm{rpm}$ and with diesel-biodiesel fuel blends of $0 \%$ (pure diesel), 5\%, 10\%, 20\%, 30\%, 40\%, 50\% and 100\% (pure biodiesel). The parameters studied were brake torque, specific fuel consumption, and fuel mass flow rate, oxides of nitrogen, carbon dioxide, and particulate matter. The results show that engine brake torque increases with the addition of biodiesel up to $5 \% B D$ with a $0.5 \%$ improvement at low speed and up to $2.5 \%$ at higher speeds. The same trend is for specific fuel consumption with $0.2 \%$ and $2.0 \%$ at lower and higher speeds, respectively. From the emissions' point of view, oxides of nitrogen increased from $12.5 \%$ at $5 \%$ BD to more than $200 \%$ at $100 \%$ BD; PM emissions were reduced with the addition of biodiesel while those for $\mathrm{CO}_{2}$ were increased. DOE analysis showed that biodiesel percentage has the most significant influence on the engine performance and emissions compared with engine speed except for the brake torque.
\end{abstract}

Keywords: Diesel-Biodiesel blend; Diesel engine; Design of Experiment; Pareto chart; Response Surface Methodology

\section{INTRODUCTION}

The demand on energy consumption has significantly increased to historical levels in Jordan. This summer has registered a historic value approaching 3.75 gigawatt in one day. Besides the huge influx of refugees from neighboring countries due to unrest, the cut in the petroleum supply that Jordan used to get from Iraq and the Gulf states at a reduced price and the economic impact of the COVID-19 pandemic has had a drastic impact on the Jordanian economy. The above factors encouraged researchers in Jordan and neighboring countries to look for alternatives from within their local resources and to try to optimize the use of these sources for best performance.

One such research that was recently published was conducted by $[1,2]$. They investigated the properties of Iraqi Associated Petroleum Gas (APG) and the possible use as fuel for internal combustion engines. They utilized the significant development in the field, which was reflected in the increasing number of up-to-date vehicle technologies being sold in Jordan and replacing old car technologies.

Several researchers investigated biodiesel-diesel fuel blends on diesel engine performance and emissions using Response Surface Methodology (RSM).

Hirkude and Belokar [3] conducted an RSM analysis of the diesel engine performance using waste palm oil biodiesel with the compression ratio, load, and fuel blends as the input variables. They reported that at the desirability of 0.75 , the optimal input parameters were Compression Ratio $(C R)=18$, Load $2.5 \mathrm{~kW}$, and fuel blend of $40 \%$ biodiesel. Another more extensive study on diesel engine performance using Diesel-Biodiesel-Butanol fuel blends was conducted by Saravanan et al. [4]. They used the Taguchi method for their study. Their main aim was to optimize the input parameters for the least Brake Specific Fuel Consumption (BSFC), Nitrogen Oxides, and smoke opacity emissions.

Saxena et al. [5] used the RSM method to investigate the effect of adding $\mathrm{TiO}_{2}$ Nano-particles to diesel-biodiesel fuel blends on the engine performance to find the optimum doping percent of Nano-particle for best results. Paramasivam [6] used the RSM-Taguchi integrated technique to optimize a single-cylinder diesel engine fuelled with Aegle marmelos (AM) de-oiled seed cake biooil opus. They reported that this method gave results of a correlation coefficient $(R)$ of 0.9787 and an average coefficient of a determination $\left(R^{2}\right)$ of 0.9119 .

Another research on the biogas-fuelled diesel engine optimization using the RSM-based Multi-Objective method was conducted by Mahla et al. [7]. He reported that the performance of the engine would significantly improve except for Carbon Monoxide (CO) and Unburned Hydrocarbon (UHC) levels, which will rise compared with the conventional diesel engine.

Sharma et al. [8] also used the RSM technique to optimize engine performance using Pongamia biodiesel/diesel fuel blends. They optimized the fuel injection pressure and timing, Pongamia biodiesel blends, and engine load to find the best engine efficiency, $B S F C$, exhaust gas temperature, and maximum cylinder pressure. They reported that the best engine input parameters were injection timing $25 \mathrm{bTDC}, 226$ bar injection pressure, $40 \%$ fuel blending, at $74 \%$ of the rated engine load.

Billa et al. [9] tested the RSM method to check its capability to predict and optimize the engine performance using Biodiesel-diesel fuel blends with the addition of Diethyl Ether and N-Octanol chemicals. Based on the desirability of 0.985 , the predicted optimum fuel blend reported was $20 \%$ biodiesel, $10 \%$ n-octanol, $2.526 \%$ DEE with $67.474 \%$ diesel.

Fuel injection parameters, e.g., timing, pressure, and engine compression ratio and their effect on engine performance using Honge oil methyl ester (HOME), were studied by Banapurmath et al. [10]. Their main aim was to establish a sort of relationship between these parameters using RSM. Based on the second-order model developed by the RSM method, they reported an increase in the brake thermal efficiency and reduced emissions when retarding the injection timing.

Shirneshan et al. [11] used the RSM method to investigate both the effects of biodiesel percentage in fuel mixture and engine operating parameters on emission characteristics of a diesel engine; the experiment was designed using Design of Experiment (DOE) based on 
RSM conducted on a four-cylinder direct-injection diesel engine. Based on the RSM model, they found that the optimum conditions for lower emission characteristics were $77.8 \%$ biodiesel percentage in the fuel mixture, $41.25 \%$ engine load at $2800 \mathrm{rpm}$ engine speed.

Heat transfer from the engine and its effect on engine first and second law parameters was studied by Yamin et al. [12] using biodiesel fuel.

Kim et al. [13] used non-esterified biodiesel to test the performance of the Direct Injection (DI) diesel engine operated at part-load conditions using the RSM method. They concluded that the injection pressure and timing were the prime influence factors regardless of the engine speed or load. They compared the optimized and experimental values for different loads. They reported that, experimentally, $B S F C=310.3 \mathrm{~g} / \mathrm{kWh}$, Nitrogen Oxides = $237 \mathrm{ppm}$ at $25 \%$ load. At $50 \%$ load, the values were 233.2 $\mathrm{g} / \mathrm{kWh}$ and $730 \mathrm{ppm}$, respectively. Tests were compared with the RSM values, which yielded to verify these estimations $300.4 \mathrm{~g} / \mathrm{kWh}$ and $277 \mathrm{ppm}$ at $25 \%$ load and $236.8 \mathrm{~g} / \mathrm{kWh}$ and $573 \mathrm{ppm}$ at $50 \%$ load, respectively.

RSM was also used by Ganapathy et al. [14] to optimize injection timing and engine operating parameters using Jatropha biodiesel.

An experimental and statistical investigation was conducted by Kumar et al. [15] to study the influence of injection timing and Exhaust Gas Recirculation (EGR) on the engine performance and emissions of a DI diesel engine. They used the RSM method for measured outputs like Nitrogen Oxides, smoke opacity, and BSFC.

Krishnamoorthi et al. [16] used the DOE tool to plan and analyze three significant parameters (indicated power, compression ratio, and indicated torque). The model proposed by the RSM method was then validated and found to have a reasonable degree of accuracy. They reported different optimum conditions for different desired output parameters. For example, they reported that for maximum thermal efficiency, the injection pressure was 230 bar and $C R=18$ with 23 bTDC injection timing. While for minimum $\mathrm{CO}$ levels, the parameters were 230 bar 18 and 25 bTDC, respectively, and those for Nitrogen Oxides levels were at 250 bar 16 with 25 bTDC, respectively.

Another work conducted by Hirkude et al. [17] used the RSM tool to optimize direct injection, single-cylinder diesel engines concerning brake power, fuel economy, and smoke emissions through experimental investigation and RSM. Results showed that this tool was useful in studying the relations between various parameters. The optimum parameters for their study based on the RSM method were found to be $C R=17.99$, injection pressure $=250 \mathrm{bar}$, and injection timing $=27 \mathrm{bTDC}$

Kannan and Anand [18] used the RSM method to optimize the injection pressure and timing for best diesel engine performance and emissions using biodiesel as a fuel. They reported that the optimum operating conditions predicted by the RSM method were injection pressure of 280 bar and timing of 25.5 bTDC. Another type of fuel blends, e.g., Butanol-Diesel, and its effect on Indirect Injection (IDI) diesel engine's performance and emissions were investigated by Yilmaz et al. [19].

In Malaysia, the feasibility of using Jatropha as feedstock for making biodiesel to be blended with diesel fuel was investigated by Mofijur et al. [20]. They then used it in different percentages to study their effect on the engine's performance and emissions characteristics.

Also, How et al. [21] conducted an experimental investigation on engine performance, emissions, and combustion and vibration characteristics with coconut biodiesel fuels.

Finally, Dwivedi et al. [22] conducted a review study on the effect of using biodiesel as a fuel for diesel engines on its performance and emissions behavior. They reported that there would be a $3-5 \%$ loss in engine power, less amount of engine wear for the same driving time, and lower emission levels except for Nitrogen Oxides and Carbon Dioxide $\left(\mathrm{CO}_{2}\right)$ when using biodiesel compared with diesel fuel.

In this research paper, the use of biodiesel made from Sunflower Oil (which is used for cooking in the School of Engineering's cafeteria at the University of Jordan) as fuel for compression ignition engines was investigated to find which of the engine input parameters are most influential in affecting the engine's output performance parameters for better control on the optimization process. Noting that at the University of Jordan, the used cooking oil has been thrown out in the sewer system, thus wasting a potential source for green energy. This wasted oil can be used to power various types of combustion systems.

\subsection{Engine Setup}

To calibrate the Diesel-RK software used for the study and to verify the model presented by the RSM method, a 4 - stroke, 4 - cylinder, direct injection, water-cooled Tempest compression ignition engine was used. The engine has a displacement of $1.5 \mathrm{~L}$.

As shown in Fig. 1, the engine is coupled to an electric dynamometer to measure the brake torque. The electric panel is equipped with an electronic display showing the engine water inlet and outlet, coolant, and exhaust temperatures.

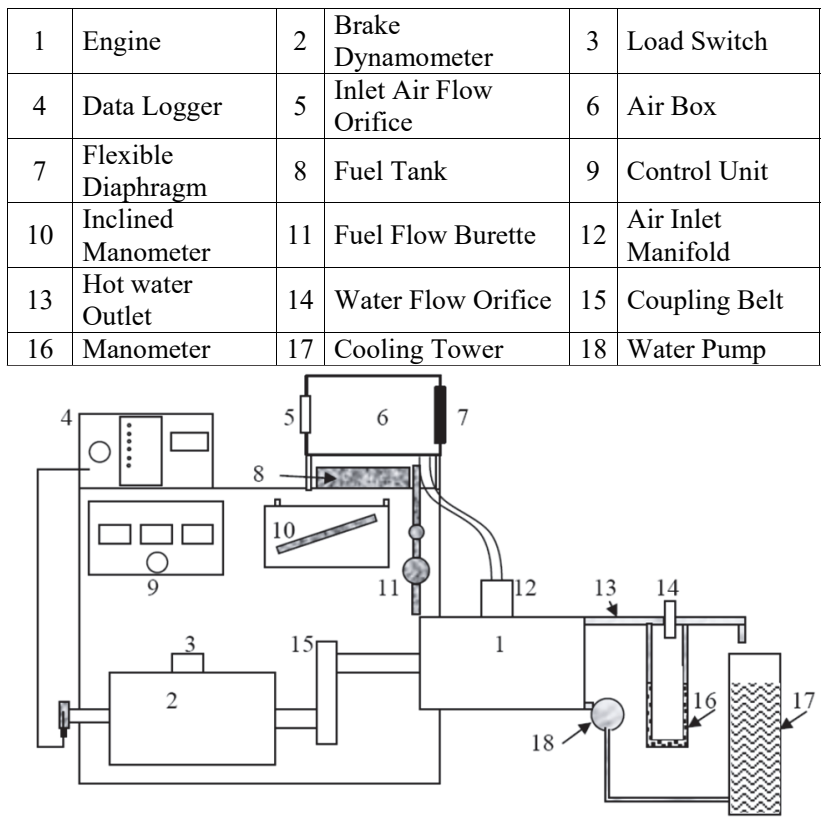

Figure 1 The experimental setup 
Before proceeding with the tests, the overall uncertainty of the setup was first evaluated. Uncertainty analysis quantifies the variation between the actual measured value of a physical quantity and the true value of the same physical quantity. Uncertainty analysis provides the experimenter a rational way of evaluating the significance of the scatter on repeated trials. This can be a powerful tool in locating the source of trouble in a misbehaving experiment, so it will be used to check the reliability of our data.

The total percentage of uncertainty of existing setup is $=$ square root of $\{\text { (uncertainty of torque })^{2}+$ (uncertainty of

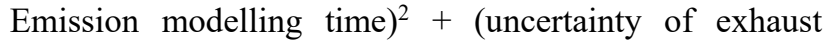

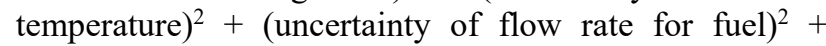
(uncertainty of airflow rate) $\left.^{2}\right\}= \pm 2.26 \%$.

This value shows that the existing setup is valid to experiment. A complete description of the fuel properties measurement and its relevant uncertainty calculations are shown in Abu Meshreft [23].

\section{MATHEMATICAL MODEL}

This theoretical study was conducted using specific verified simulation software, i.e., DIESEL-RK, a full-cycle thermodynamic engine simulation software. The study was performed using a 4 - stroke, 4 - cylinder, water-cooled, direct injection Compression Ignition Engine (CIE). The engine specifications are shown in Tab. 1.

Table 1 Engine design and operating parameters
\begin{tabular}{|l|l|}
\hline Parameter & Dimensions \\
\hline Diameter $\times$ Stroke & $72.25 \mathrm{~mm} \times 88.2 \mathrm{~mm}$ \\
\hline Engine Speed & $1000-3600 \mathrm{rpm}$ \\
\hline Compression Ratio & 22 \\
\hline Inlet Valve - Open & $15^{\circ} \mathrm{bTDC}$ \\
- Close & $25^{\circ} \mathrm{aBDC}$ \\
\hline Exhaust Valve - Open & $13^{\circ} \mathrm{bTDC}$ \\
- Close & $20^{\circ} \mathrm{aBDC}$ \\
\hline Load & Full load (Rack) opening \\
\hline
\end{tabular}

\subsection{Brief Description of the Diesel-RK Model}

In this section, the key equations of the Diesel-RK model have been shown. Complete detail of the model is shown in other well documented papers [24, 25].

\subsubsection{In Cylinder Combustion Modelling Equations}

The basic governing equations defining the small change in cylinder gas temperature, pressure and its composition are derivable from the equation of state. The general quasi-steady flow energy equation in differential form for any control volume is given by:

$$
\sum \frac{\mathrm{d} Q_{i}}{\mathrm{~d} t}-2 \sum \frac{\mathrm{d} W_{k}}{\mathrm{~d} t}=\frac{\mathrm{d}}{\mathrm{d} t}(m \cdot u)-\sum \frac{\mathrm{d} m_{j}}{\mathrm{~d} t}\left(h_{j}+\frac{V_{j}^{2}}{2 g_{c}}+\frac{z \cdot g}{g_{c}}\right)
$$

Assuming negligible change in kinetic and potential energy of the streams and zero shaft work, the energy equation can be written as:

$$
\sum \frac{\mathrm{d} Q_{i}}{\mathrm{~d} t}-2 \sum \frac{\mathrm{d} W_{k}}{\mathrm{~d} t}=\frac{\mathrm{d}}{\mathrm{d} t}(m . u)-\sum \frac{\mathrm{d} m_{j}}{\mathrm{~d} t}\left(h_{j}\right)
$$

$\sum \frac{\mathrm{d} W_{k}}{\mathrm{~d} t}=P \frac{\mathrm{d} V}{\mathrm{~d} t}$

By using equation of state and expressing internal energy $u$ as a function of temperature and composition, the rate of change of temperature with respect to crank angle $\theta$ is given by:

$$
\begin{aligned}
& \frac{\mathrm{d} T}{\mathrm{~d} \theta}=\sum \frac{\mathrm{d} Q_{i}}{\mathrm{~d} \theta}-\frac{m R T}{V} \frac{\mathrm{d} V}{\mathrm{~d} \theta}+\sum \frac{\mathrm{d} m_{j}}{\mathrm{~d} \theta}\left(h_{j}\right)- \\
& -u \sum \frac{\mathrm{d} m_{j}}{\mathrm{dt}}-\frac{m \cdot \frac{\delta u d F}{\delta F d \theta}}{m \cdot C_{v}}
\end{aligned}
$$

which is valid for all 'quasi-steady, control volumes.

The gas pressure and temperature during the compression stage are calculated using the following equations:

$$
\begin{aligned}
& \frac{\mathrm{d} P}{\mathrm{~d} \theta}=\frac{\left[-\left(1+\frac{R}{C_{v}}\right) \cdot P \cdot \frac{\mathrm{d} V}{\mathrm{~d} \theta}-\frac{R d Q_{c r}}{C_{v}}+\frac{R d Q_{h t}}{C_{v} \mathrm{~d} \theta}\right]}{V} \\
& \frac{\mathrm{d} T}{\mathrm{~d} \theta}=T \cdot\left(\frac{1}{P} \frac{d P}{d \theta}+\frac{1}{V} \frac{d V}{d \theta}\right)
\end{aligned}
$$

The numerical method used for this purpose is the Runge-Kutta method.

The instantaneous cylinder volume measured from BDC position, which is a function of the crank-angle and the geometry of tile slider-crank, can be expressed as:

$$
V(\theta)=V_{s}\left[\left(\frac{C R}{C R-1}\right)-\left(\frac{1-\cos \theta}{2}\right)+\left(\frac{C R L}{S}\right)-\frac{1}{2} \sqrt{\left(\frac{2 \cdot C R L}{S}\right)^{2}-\sin ^{2} \theta}\right]
$$

By differentiating the Eq. (7), the rate of change of cylinder volume with crank angle is given by:

$\frac{\mathrm{d} V}{\mathrm{~d} \theta}=\frac{V_{s}}{2} \sin \theta\left[\frac{\cos \theta}{\left(\frac{2 \cdot C R L}{S}\right)^{2}-\sin ^{2} \theta}-1\right]$

The extra governing equations are also used to compute work output and heat loss:

$$
\begin{aligned}
& \frac{\mathrm{d} W}{\mathrm{~d} \theta}=P \frac{\mathrm{d} V}{\mathrm{~d} \theta} \\
& \frac{\mathrm{d} Q_{W}}{\mathrm{~d} \theta}=\frac{h_{W}}{\omega}\left[A_{b}\left(T_{b}-T_{w}\right)+A_{u}\left(T_{u}-T_{w}\right)\right]
\end{aligned}
$$

where; suffix $b$ denotes the burned side, $u$ for the unburned side and $w$ for the cylinder wall.

The Heat Transfer Coefficient $\left(h_{w}\right)$ from gas to walls is calculated by G. Woschni's formula [26]: 
$h_{W}=\frac{P^{0.8} V^{0.8}}{T^{0.53} D^{0.2}}$

where:

$V=6.18 C_{m}$ is a gas velocity during scavenging and intake stroke, $V=2.28 C_{m}$ is a gas velocity during compression stroke, $V=2.28 C_{m}+0.00324 \frac{V_{s} T_{a}}{P_{a} V_{a}}\left(P-P_{\text {motored }}\right)$ is the gas velocity during the other strokes.

$C_{m}$ - mean piston speed in $\mathrm{m} / \mathrm{s}$.

$P_{a}, T_{a}, V_{a}$ are pressure, temperature, and volume of cylinder at beginning of compression (IVC) respectively; $P_{\text {motored }}$ is a cylinder pressure under motored conditions (without combustion).

During the simulation, the assumption is made that the heat release process consists of four main phases. They differ by physical and chemical peculiarities and factors limiting the rate of the process:

- Induction period.

- Premixed combustion phase.

- Mixing-controlled combustion phase.

- Late combustion phase after the ending of fuel injection.

The autoignition delay period $\tau_{i}$ is calculated by modified Tolstov's equation [27]:

$\tau_{i}=3.8 \cdot 10^{-6}\left(1-1.6 \cdot 10^{-4} N\right) \sqrt{\frac{T}{P}} \exp \left(\frac{E_{a}}{8.312 T} \frac{70}{C N+25}\right)$

During premixed combustion phase the heat release rate is:

$\frac{\mathrm{d} x}{\mathrm{~d} \tau}=\varnothing_{0} A_{0}\left(\frac{m_{f}}{v_{i}}\right)\left(\sigma_{u d}-x\right)\left(0.1 \sigma_{u d}+x_{0}\right)+\varnothing_{1} \frac{\mathrm{d} \sigma_{u}}{\mathrm{~d} \tau}$

During mixing-controlled combustion phase, heat release rate is:

$\frac{\mathrm{d} x}{\mathrm{~d} \tau}=\varnothing_{1} \frac{\mathrm{d} \sigma_{u}}{\mathrm{~d} \tau}+\varnothing_{2} A_{2}\left(\frac{m_{f}}{v_{c}}\right)\left(\sigma_{u}-x\right)(\varphi-x)$

After fuel injection, at late combustion phase the heat release rate is:

$$
\frac{\mathrm{d} x}{\mathrm{~d} \tau}=\varnothing_{3} A_{3} K_{T}(1-x)\left(\xi_{b} \varphi-x\right)
$$

In these equations it is assumed that $\varnothing_{0} \approx \varnothing_{1} \approx \varnothing_{2} \approx \varnothing$ a function describing completeness of fuel vapor combustion in the zones:

$\varnothing=1-\frac{A_{1}}{\xi_{b} \alpha-x}\left\{r_{v}+\sum_{i=1}^{m v}\left[300 r_{w i} \exp \left(\frac{-16000}{2500+T_{w i}}\right)\right]\right\} \frac{\mathrm{d} x}{\mathrm{~d} \tau}$

where: $\xi_{b}$ is an efficiency of air use, $\alpha$ is an equivalence $A / F$ ratio, $r_{v}$ is a relative evaporation rate in the zones of environment and front, $r_{w i}$ is relative evaporation rate in the different zones of WSF: $r_{v}=\frac{\left(\frac{\mathrm{d} \sigma_{u} \text { env }}{\mathrm{d} \tau}+\frac{\mathrm{d} \sigma_{u} \text { front }}{\mathrm{d} \tau}\right)}{\left(\frac{\mathrm{d} \sigma_{u}}{\mathrm{~d} \tau}\right)}$

$r_{w i}=\frac{\left(\frac{\mathrm{d} \sigma_{u w i}}{\mathrm{~d} \tau}\right)}{\left(\frac{\mathrm{d} \sigma_{u}}{\mathrm{~d} \tau}\right)}$

$m_{W}$ is a current number of zones formed by WS.

The efficiency of air use $\xi_{b}$ is a function of the current equivalence ratio in the combustion zone to the overall $A / F$ ratio in cylinder defined as $\alpha$.

On the basis of gas analysis testing for different diesel engines, the $\xi_{b}$ expression was obtained by Razleytsev $[24,25]$ in the form:

$\xi_{b}=1-1.46\left(1-\xi_{b 0}\right) \frac{\overline{\theta_{z}}}{\overline{\theta_{z 0}}} \frac{2}{\pi} \exp \left[-\frac{1}{2}\left(\frac{\overline{\theta_{z}}}{\overline{\theta_{z 0}}}\right)^{2}\right]$

where: $\theta_{z 0}=0.25 \ldots . .0 .35$ is a constant, $\theta_{z}=\frac{\theta}{\theta_{z}}$ is a current CA from combustion beginning $(\theta)$ related to conventional combustion duration $\theta_{z}, \xi_{b 0}=0.45 \ldots 0.55$ for diesels with compact piston bowl, and $\xi_{b 0}=0.40 \ldots .0 .45$ for medium and high speed diesels with open combustion chamber (Hesselman).

Based on experience, RK-model calibration for different engines allows recommending the following:

$$
A_{0}=a_{0} \sqrt{\left(R_{s} n\right)} ; A_{1}=\frac{0.04}{\sqrt{\left(R_{s} n\right)}} \text { and } A_{2}=9 \sqrt{\left(R_{s} n\right)}
$$

\subsubsection{Modelling Nitrogen Oxides Formation}

In the simulation of nitrogen oxides formation the cylinder is divided into two zones: fresh charge and burnt gas zones. The fresh charge zone consists of air, fuel and residual gas. Before combustion the fresh charge zone exists alone.

Because in the engine the "thermal" NO are the main, all calculations are carried out with thermal mechanism.

The chain mechanism for the oxidation of nitrogen is shown below:

$\mathrm{O}_{2}<=>2 \mathrm{O}$

$\mathrm{N}_{2}+\mathrm{O}<=>\mathrm{NO}+\mathrm{N}$

$\mathrm{N}+\mathrm{O}_{2}<=>\mathrm{NO}+\mathrm{O}$

the third reaction being the main reaction. The rate of this reaction depends on concentration of atomic oxygen.

The calculation of NO formation is carried out for the combustion zone, then the intermediate NO concentration over whole combustion chamber is determined. Volume concentration of $\mathrm{NO}$ in combustion products formed in a current calculation step is defined by equation: 


$$
\frac{\mathrm{d}[\mathrm{NO}]}{\mathrm{d} \tau}=\frac{2.333 \cdot 10^{7} P \mathrm{e}^{-\frac{38020}{T_{b}}}\left[\mathrm{~N}_{2}\right]_{e q}[\mathrm{O}]_{e q}\left[1-\left(\frac{[\mathrm{NO}]}{[\mathrm{NO}]_{e q}}\right)\right]}{R T_{b}\left[1+\frac{2346}{T_{b}} \mathrm{e}^{-\frac{3365}{T_{b}}} \frac{[\mathrm{NO}]}{\left[\mathrm{O}_{2}\right]_{e q}}\right]} \frac{1}{\omega}
$$

where: $[\mathrm{NO}]_{\mathrm{eq}},\left[\mathrm{N}_{2}\right]_{\mathrm{eq}},[\mathrm{O}]_{\mathrm{eq}},\left[\mathrm{O}_{2}\right]_{\mathrm{eq}}$ are equilibrium concentrations of a nitrogen oxide, molecular nitrogen, atomic and molecular oxygen, respectively.

\subsubsection{Modelling Soot formation}

This method for the simulation of soot formation and burning in diesel cylinder was developed by Dr. Razleitsev [27]. The method takes into account features of sprayed fuel burning. It is assumed the soot is formed mainly by two ways:

- $\quad$ As a result of chain destructive transformation of molecules of fuel diffusing from the surface of drops to the front of a flame.

- Owing to high-temperature thermal polymerization and dehydrogenization of a vapor-liquid core of evaporating drops.

Parallel to this, the process of burning of soot particles and reduction of their volumetric concentration owing to expansion occurs.

Detailed description of equations is presented in [19, 20, 24-26], therefore only end formulas are presented in this page.

Soot formation rate in a burning zone is given in the following equation:

$$
\left(\frac{\mathrm{d}[\mathrm{C}]}{\mathrm{d} t}\right)_{K}=0.004 \frac{m_{f}}{V} \frac{\mathrm{d} x}{\mathrm{~d} t}
$$

Soot formation rate due to high-temperature thermal polymerization of drops nucleuses is proportionate to rate of disappearance of drops because of full evaporation.

Soot formation during injection period:

$$
\left(\frac{\mathrm{d}[\mathrm{C}]}{\mathrm{d} t}\right)_{\Pi}=1.7 \frac{m_{f}}{V} \frac{1-\mathrm{e}\left[-\left(\frac{\sqrt{K t}}{d_{32}}\right)^{n}\right]}{\theta_{i n j}}
$$

where: $\theta_{i n j}$ is an injection duration, $n$ is a factor of distribution (for diesels injectors $=2$ to 4 ), $K$ is a constant of evaporation.

After the end-of-injection:

$$
\left(\frac{\mathrm{d}[\mathrm{C}]}{\mathrm{d} t}\right)_{\Pi}=0.0028\left(1-x_{\text {end_inj }}\right) \frac{n m_{f}}{2 V t_{2}}\left(\frac{\sqrt{K t}}{d_{32}}\right) \mathrm{e}^{\left[-\left(\frac{\sqrt{K t}}{d_{32}}\right)^{n}\right]}
$$

where: $t_{2}$ is a current time after injection termination;

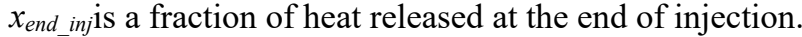

The rate of soot burning is given by the following equation:
$\left(\frac{\mathrm{d}[\mathrm{C}]}{\mathrm{d} t}\right)_{B}=3.1 \times 10^{-6} \sqrt{N} P[\mathrm{C}]$

Rate of soot concentration decrease because of expansion as shown in this equation:

$\left(\frac{\mathrm{d}[\mathrm{C}]}{\mathrm{d} t}\right)_{V}=0.75 \frac{6 N}{V} \frac{\mathrm{d} V}{\mathrm{~d} \theta}[\mathrm{C}]$

Finally, the resulting rate of soot formation and burning is given by:

$\frac{\mathrm{d}[\mathrm{C}]}{\mathrm{d} t}=B\left(\frac{\mathrm{d}[\mathrm{C}]}{\mathrm{d} t}\right)_{K}+B\left(\frac{\mathrm{d}[\mathrm{C}]}{\mathrm{d} t}\right)_{\Pi}-\frac{1}{B}\left(\frac{\mathrm{d}[\mathrm{C}]}{\mathrm{d} t}\right)_{B}-\left(\frac{\mathrm{d}[\mathrm{C}]}{\mathrm{d} t}\right)_{V}$

where $B=A\left(\frac{N_{f c}}{N}\right)^{m}$ is an empirical factor, $N_{f c}$ is the engine speed at full capacity, $A, m$ are calibrate coefficients.

Exhaust gas soot concentration related to normal conditions:

$[\mathrm{C}]=\int_{\theta_{0}}^{60}\left\{\frac{\mathrm{d}[\mathrm{C}]}{\mathrm{d} t} \frac{\mathrm{d} \theta}{\mathrm{d} N}\left(\frac{0.1}{P_{\theta=60^{\circ}}}\right)^{\frac{1}{K}}\right\}$

where: $P_{\theta=60^{\circ}}$ is a cylinder pressure at $60^{\circ}$ before BDC, $k$ is an exhaust gas adiabatic exponent (1.33).

Hartridge smoke level is given by the following equation:

Hartridge $=100\left[1-0.95 \mathrm{e}^{(-2.4226[\mathrm{C}])}\right]$

Particulate Matter emission is calculated using Alkidas equation [28] as a function of Bosch smoke number:

$[P M]=565\left(\ln \left(\frac{10}{10-\text { Bosch }}\right)\right)^{1.206}$

An experimental curve was used to calculate the Bosch smoke number (BSN) as a function of Hartridge equation.

\subsection{Model Verification}

Before discussing our results, we need to check the validity of our model. The experimental data obtained from the engine were used and compared with those obtained from the model under the same conditions of atmospheric conditions, fuel and its properties and by tuning certain parameters like friction coefficient to give peak cylinder pressure and frictional losses, besides tuning other emission parameters. Fig. 2 below show that our model is valid, and we can predict the performance of the engine to a reasonable degree of accuracy. These figures were taken with compression ratio $=22$, injection timing $20^{\circ}$ Before Top Dead Center (bTDC) full rack opening. The fuel properties were obtained from Al-Hamamreh and Yamin [29]. 

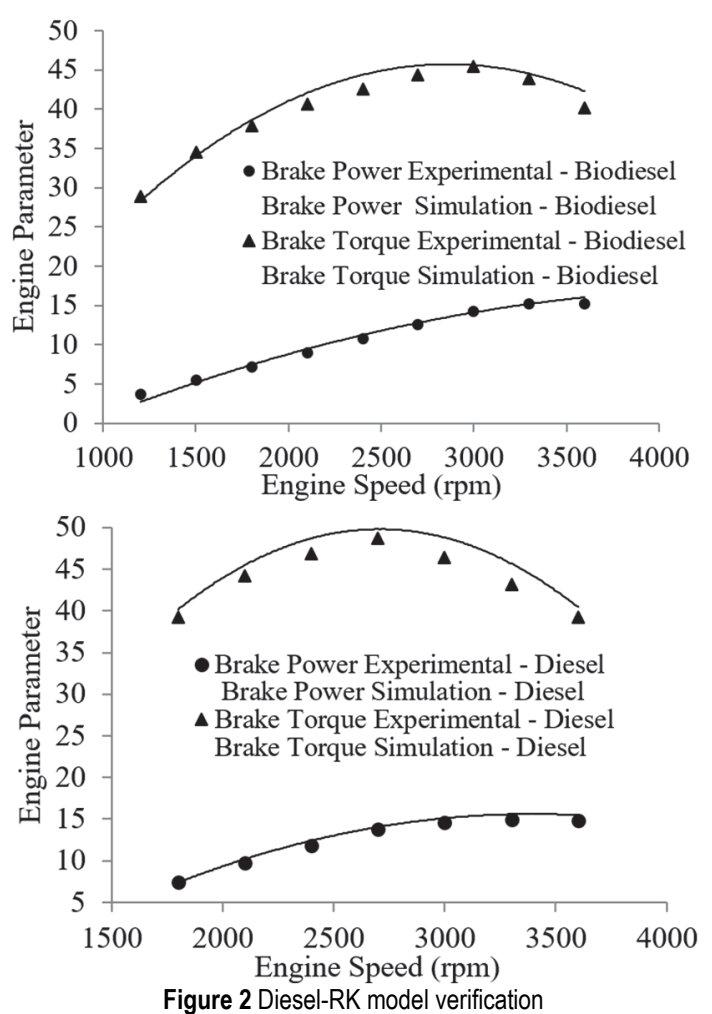

\subsection{Response Surface Methodology (RSM)}

One of the successful mathematical tools used for modeling, analyzing, and optimizing engineering problems that are affected by some variables is Heydari-Maleney et al. [30].

The theory behind this method and its importance in engineering analysis was explained by Montgomery and Douglas [31].

The prime objective of using RSM is to obtain a fair and accurate relationship between a group of controllable input variables $\left(x_{1}, x_{2}, \ldots, x_{n}\right)$ and an output performance $(y)$. This data was modeled using second-order polynomial models shown in Eq. (34).
$Y=\beta_{0}+\sum_{i=1}^{k} \beta_{i} X_{i}+\sum_{i=1}^{k} \beta_{i i} X_{i}^{2}+\sum_{j \geq i}^{k} \beta_{i j} X_{i} X_{j}+\varepsilon$

where $Y$ is the response, $X_{i}$ are values of the numeric factors, terms $\beta_{0}, \beta_{i}, \beta_{i i}$ and $\beta_{i j}$ are regression coefficients, $i$ and $j$ are linear and quadratic coefficients, and $\varepsilon$ is the data error.

Surface plots of the output $(Y)$ with the input factors $(X)$ were constructed using these fitted models. The model was applied to find the interaction relationship between engine input variables and responses.

In this research, the two independent parameters were A: engine speed (rpm) and B: biodiesel percentage in the fuel blend (\%). Engine performance and emissions parameters, e.g., brake torque, brake specific fuel consumption, fuel consumption rate, oxides of nitrogen, etc., were the chosen response.

The ranges and levels of the chosen independent parameters were $1200 \mathrm{rpm}(\mathrm{min})$ to $3600 \mathrm{rpm}(\max )$ with the middle point taken at $2400 \mathrm{rpm}$ for the engine speed. As for the biodiesel percentage, the minimum value taken was $0 \%$ (pure diesel fuel), and the maximum of $100 \%$ (pure biodiesel fuel). Both of the variables were fed into the system as Numerical.

The details of the experimental design, as given by the RSM method with 72 experiments, are shown in Tab. 3 . The experimental results were investigated using RSM using the MINITAB19 code. The data used for the MINITAB model is summarized in Tab. 2.

\subsection{Verification of the Statistical Model}

The statistical models predicted by the DOE method were verified for $40 \% B D$. This is to test the accuracy of the model. This is shown below in Fig. 3 .

The overall error between the experimental and predicted data for the whole range of test did not exceed $3 \%$. Hence; the model was considered to be accurate enough for further study.
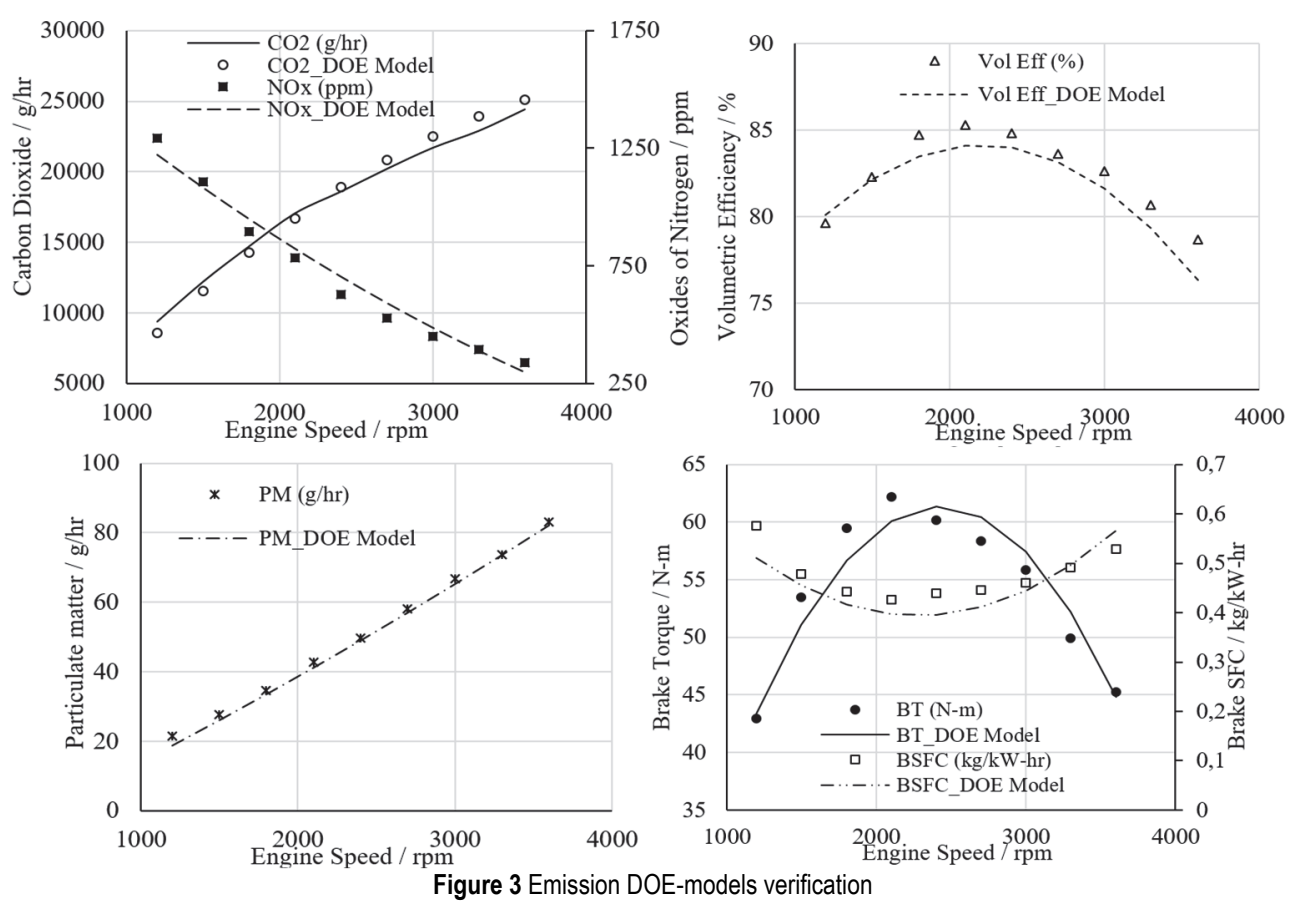
Table 2 Experimental design based on BBD method

\begin{tabular}{|c|c|c|c|c|c|c|c|c|c|c|c|c|c|}
\hline $\begin{array}{c}N / \\
\mathrm{rpm}\end{array}$ & $\begin{array}{c}B D / \\
\%\end{array}$ & $\begin{array}{c}B T \\
/ \mathrm{Nm}\end{array}$ & $\begin{array}{c}\text { Vol Eff } \\
/ \%\end{array}$ & $\begin{array}{c}B S F C \\
/ \mathrm{kg} / \mathrm{kW}-\mathrm{hr}\end{array}$ & $\begin{array}{c}m_{f} \\
/ \mathrm{g} / \mathrm{s}\end{array}$ & $\begin{array}{l}T_{\max } \\
/ \mathrm{K}\end{array}$ & $\begin{array}{l}\text { NOx } \\
/ \text { ppm }\end{array}$ & $\begin{array}{l}\mathrm{CO}_{2} \\
/ \mathrm{g} / \mathrm{hr}\end{array}$ & $\begin{array}{c}P M \\
/ \mathrm{g} / \mathrm{hr}\end{array}$ & Std Order & Run Order & Blocks & Pt Type \\
\hline 1200 & 0 & 45.25 & 79.501 & 0.5146 & 0.81 & 2494.7 & 800.16 & 9507.91 & 22.37 & 1 & 1 & 1 & 1 \\
\hline 1500 & 0 & 56.26 & 82.053 & 0.4271 & 1.05 & 2509.6 & 778.51 & 12350.23 & 28.86 & 2 & 2 & 1 & 1 \\
\hline 1800 & 0 & 62.73 & 84.04 & 0.3919 & 1.29 & 2551.6 & 743.29 & 15200.31 & 37.15 & 3 & 3 & 1 & 1 \\
\hline 2100 & 0 & 66.93 & 84.867 & 0.3713 & 1.52 & 2526.3 & 623.43 & 17940.92 & 44.08 & 4 & 4 & 1 & 1 \\
\hline 2400 & 0 & 67.34 & 84.153 & 0.3660 & 1.72 & 2591.3 & 638.16 & 20187.02 & 53.68 & 5 & 5 & 1 & 1 \\
\hline 2700 & 0 & 66.72 & 82.963 & 0.3641 & 1.91 & 2588.1 & 551.32 & 22619.29 & 61.49 & 6 & 6 & 1 & 1 \\
\hline 3000 & 0 & 66.07 & 81.936 & 0.3632 & 2.09 & 2590.4 & 508.78 & 24700.12 & 72.34 & 7 & 7 & 1 & 1 \\
\hline 3300 & 0 & 60.57 & 79.929 & 0.3776 & 2.20 & 2590.3 & 474.66 & 26016.99 & 82.83 & 8 & 8 & 1 & 1 \\
\hline 3600 & 0 & 56.10 & 77.971 & 0.3978 & 2.34 & 2591.9 & 355.38 & 27474.89 & 87.05 & 9 & 9 & 1 & 1 \\
\hline 1200 & 5 & 45.49 & 79.405 & 0.5150 & 0.82 & 2533.4 & 900.63 & 9205.088 & 23.59 & 10 & 10 & 1 & 1 \\
\hline 1500 & 5 & 56.68 & 81.915 & 0.4261 & 1.05 & 2530.5 & 787.69 & 11857.33 & 30.80 & 11 & 11 & 1 & 1 \\
\hline 1800 & 5 & 63.78 & 84.158 & 0.3892 & 1.30 & 2598.9 & 831.09 & 14565.83 & 39.67 & 12 & 12 & 1 & 1 \\
\hline 2100 & 5 & 67.72 & 84.814 & 0.3694 & 1.53 & 2549.1 & 649.87 & 17133.73 & 47.24 & 13 & 13 & 1 & 1 \\
\hline 2400 & 5 & 67.82 & 83.815 & 0.3645 & 1.73 & 2647.3 & 753.43 & 19311.31 & 58.22 & 14 & 14 & 1 & 1 \\
\hline 2700 & 5 & 67.56 & 82.631 & 0.3608 & 1.91 & 2665.8 & 708.64 & 21288.06 & 69.33 & 15 & 15 & 1 & 1 \\
\hline 3000 & 5 & 66.79 & 81.633 & 0.3606 & 2.10 & 2665.2 & 628.03 & 23464.44 & 78.95 & 16 & 16 & 1 & 1 \\
\hline 3300 & 5 & 61.43 & 79.658 & 0.3738 & 2.20 & 2673 & 586.16 & 24474.45 & 90.69 & 17 & 17 & 1 & 1 \\
\hline 3600 & 5 & 57.54 & 77.791 & 0.3897 & 2.35 & 2637.5 & 481.21 & 25895.94 & 96.74 & 18 & 18 & 1 & 1 \\
\hline 1200 & 10 & 45.60 & 79.651 & 0.5194 & 0.83 & 2495.1 & 849.78 & 9222.93 & 22.97 & 19 & 19 & 1 & 1 \\
\hline 1500 & 10 & 56.37 & 82.041 & 0.4325 & 1.06 & 2515.8 & 854.73 & 11899.24 & 30.60 & 20 & 20 & 1 & 1 \\
\hline 1800 & 10 & 63.23 & 84.244 & 0.3959 & 1.31 & 2556.2 & 803.09 & 14624.48 & 38.79 & 21 & 21 & 1 & 1 \\
\hline 2100 & 10 & 67.04 & 84.858 & 0.3761 & 1.54 & 2527.8 & 672.81 & 17171.16 & 46.64 & 22 & 22 & 1 & 1 \\
\hline 2400 & 10 & 67.42 & 84.135 & 0.3708 & 1.75 & 2596.4 & 706.74 & 19431.41 & 55.59 & 23 & 23 & 1 & 1 \\
\hline 2700 & 10 & 66.88 & 82.937 & 0.3685 & 1.94 & 2595.4 & 623.89 & 21564.26 & 64.04 & 24 & 24 & 1 & 1 \\
\hline 3000 & 10 & 66.19 & 81.909 & 0.3677 & 2.12 & 2601.2 & 573.68 & 23621.98 & 74.34 & 25 & 25 & 1 & 1 \\
\hline 3300 & 10 & 60.81 & 79.912 & 0.3817 & 2.23 & 2605.0 & 519.24 & 24643.85 & 83.69 & 26 & 26 & 1 & 1 \\
\hline 3600 & 10 & 56.41 & 77.914 & 0.4011 & 2.37 & 2601.4 & 421.23 & 25965.71 & 89.98 & 27 & 27 & 1 & 1 \\
\hline 1200 & 20 & 44.74 & 79.603 & 0.5367 & 0.84 & 2466.0 & 907.51 & 9077.16 & 22.46 & 28 & 28 & 1 & 1 \\
\hline 1500 & 20 & 55.66 & 82.193 & 0.4454 & 1.08 & 2468.8 & 901.95 & 11754.87 & 29.75 & 29 & 29 & 1 & 1 \\
\hline 1800 & 20 & 61.95 & 84.132 & 0.4092 & 1.33 & 2516.2 & 874.88 & 14503.20 & 36.94 & 30 & 30 & 1 & 1 \\
\hline 2100 & 20 & 65.72 & 84.978 & 0.3900 & 1.57 & 2534.5 & 711.81 & 16867.10 & 45.05 & 31 & 31 & 1 & 1 \\
\hline 2400 & 20 & 66.02 & 84.237 & 0.3848 & 1.77 & 2528.6 & 680.97 & 19274.58 & 53.52 & 32 & 32 & 1 & 1 \\
\hline 2700 & 20 & 65.44 & 83.072 & 0.3829 & 1.97 & 2526.3 & 596.08 & 21218.36 & 61.41 & 33 & 33 & 1 & 1 \\
\hline 3000 & 20 & 64.40 & 82.095 & 0.3845 & 2.16 & 2505.1 & 518.27 & 23277.55 & 69.68 & 34 & 34 & 1 & 1 \\
\hline 3300 & 20 & 58.88 & 80.1 & 0.4009 & 2.27 & 2538.2 & 449.27 & 23963.61 & 77.27 & 35 & 35 & 1 & 1 \\
\hline 3600 & 20 & 54.50 & 78.108 & 0.42252 & 2.41 & 2504.2 & 386.04 & 25093.82 & 86.33 & 36 & 36 & 1 & 1 \\
\hline 1200 & 30 & 44.01 & 79.678 & 0.55459 & 0.85 & 2435.2 & 1163.7 & 9346.90 & 21.81 & 37 & 37 & 1 & 1 \\
\hline 1500 & 30 & 54.60 & 82.205 & 0.46108 & 1.10 & 2457.6 & 1034.2 & 12041.16 & 28.98 & 38 & 38 & 1 & 1 \\
\hline 1800 & 30 & 60.90 & 84.196 & 0.42298 & 1.35 & 2480.3 & 978.39 & 14843.83 & 36.17 & 39 & 39 & 1 & 1 \\
\hline 2100 & 30 & 64.40 & 85.042 & 0.4044 & 1.59 & 2501.4 & 825.83 & 17313.77 & 44.00 & 40 & 40 & 1 & 1 \\
\hline 2400 & 30 & 64.90 & 84.337 & 0.39789 & 1.80 & 2487.6 & 762.09 & 19715.68 & 51.96 & 41 & 41 & 1 & 1 \\
\hline 2700 & 30 & 64.00 & 83.179 & 0.39802 & 2.00 & 2524.3 & 668.72 & 21568.72 & 59.64 & 42 & 42 & 1 & 1 \\
\hline 3000 & 30 & 62.42 & 82.224 & 0.4034 & 2.20 & 2505.4 & 542.7 & 23498.88 & 67.54 & 43 & 43 & 1 & 1 \\
\hline 3300 & 30 & 56.42 & 80.274 & 0.42581 & 2.31 & 2464.7 & 451.12 & 24519.93 & 74.23 & 44 & 44 & 1 & 1 \\
\hline 3600 & 30 & 51.61 & 78.323 & 0.45425 & 2.46 & 2442.5 & 371.58 & 25643.43 & 82.63 & 45 & 45 & 1 & 1 \\
\hline 1200 & 50 & 42.62 & 127.84 & 0.5933 & 0.88 & 127.84 & 1857.3 & 9522.96 & 21.62 & 55 & 55 & 1 & 1 \\
\hline 1500 & 50 & 52.51 & 129.12 & 0.49526 & 1.13 & 129.12 & 1521.2 & 12277.93 & 27.83 & 56 & 56 & 1 & 1 \\
\hline 1800 & 50 & 58.46 & 129.01 & 0.45798 & 1.40 & 129.01 & 1212.4 & 14853.72 & 34.56 & 57 & 57 & 1 & 1 \\
\hline 2100 & 50 & 61.13 & 127.87 & 0.44063 & 1.65 & 127.87 & 1018 & 17331.56 & 42.78 & 58 & 58 & 1 & 1 \\
\hline 2400 & 50 & 59.49 & 124.89 & 0.45052 & 1.87 & 124.89 & 737 & 18869.99 & 50.33 & 59 & 59 & 1 & 1 \\
\hline 2700 & 50 & 57.31 & 121.91 & 0.46134 & 2.08 & 121.91 & 668.94 & 20372.51 & 58.90 & 60 & 60 & 1 & 1 \\
\hline 3000 & 50 & 55.19 & 119.19 & 0.47304 & 2.28 & 119.19 & 588.96 & 22019.87 & 67.53 & 61 & 61 & 1 & 1 \\
\hline 3300 & 50 & 48.74 & 113.23 & 0.51097 & 2.39 & 113.2 & 496.5 & 22615.50 & 74.82 & 62 & 62 & 1 & 1 \\
\hline 3600 & 50 & 44.81 & 110.05 & 0.54212 & 2.54 & 110.05 & 443.1 & 24329.76 & 84.30 & 63 & 63 & 1 & 1 \\
\hline 1200 & 100 & 39.31 & 79.658 & 0.69472 & 0.95 & 2401.5 & 3260 & 9814.108 & 22.23 & 64 & 64 & 1 & 1 \\
\hline 1500 & 100 & 49.24 & 82.365 & 0.57346 & 1.23 & 2365.3 & 3111.1 & 12690.66 & 28.53 & 65 & 65 & 1 & 1 \\
\hline 1800 & 100 & 54.84 & 84.387 & 0.52705 & 1.51 & 2368.2 & 2999.8 & 15662.86 & 35.71 & 66 & 66 & 1 & 1 \\
\hline 2100 & 100 & 57.67 & 85.254 & 0.5068 & 1.79 & 2316.6 & 2723.4 & 18400.49 & 44.07 & 67 & 67 & 1 & 1 \\
\hline 2400 & 100 & 57.61 & 84.618 & 0.50344 & 2.02 & 2311.3 & 2632.9 & 20809.45 & 51.81 & 68 & 68 & 1 & 1 \\
\hline 2700 & 100 & 56.25 & 83.485 & 0.50874 & 2.25 & 2291.3 & 2405 & 23089.63 & 60.13 & 69 & 69 & 1 & 1 \\
\hline 3000 & 100 & 54.70 & 82.495 & 0.51695 & 2.47 & 2257.4 & 2187.2 & 25394.78 & 69.08 & 70 & 70 & 1 & 1 \\
\hline 3300 & 100 & 48.28 & 80.576 & 0.55907 & 2.59 & 2206.9 & 1939.4 & 26691.20 & 77.53 & 71 & 71 & 1 & 1 \\
\hline 3600 & 100 & 43.93 & 78.597 & 0.59943 & 2.76 & 2179.8 & 1755 & 28382.57 & 87.41 & 72 & 72 & 1 & 1 \\
\hline
\end{tabular}

\section{RESULTS \& DISCUSSION}

\subsection{Engine Performance}

Engine performance parameters studied were the brake torque, brake-specific fuel consumption, combustion duration, heat release rate, and peak cylinder pressure and temperature.

\subsubsection{Brake Torque (BT)}

The quadratic model used to fit the data for engine torque based on the independent input variables as determined using the RSM technique is shown in Eq. (35) below. The accuracy of this model, as determined by the RSM method, is $R^{2}($ Adj $)=94 \%$. 


$$
\begin{aligned}
& B T=-6.07+0.05980 N-0.1180 B D-0.000012 N^{2}+ \\
& +0.001000 B D^{2}-0.000040 N \cdot B D
\end{aligned}
$$

Fig. $4 \mathrm{a}$ and Fig. $4 \mathrm{~b}$ show the two-dimensional presentation on the effect of engine speed $(N)$ and Biodiesel percentage in the blend $(B D / \%)$ on the brake torque $(B T)$ and the Pareto chart for the main effects of the variables on $B T$.

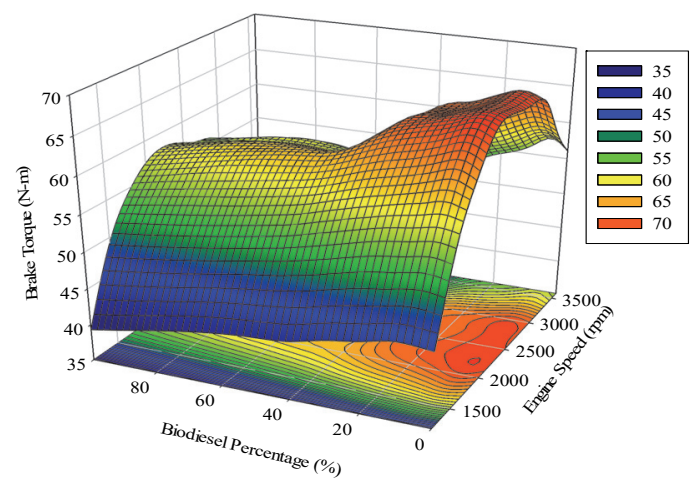

(a)
Fig. 4 a clearly shows that at $5 \% B D$, there is a slight increase in $B T$ from $0.5 \%$ at lower engine speeds to $2.5 \%$ at higher engine speeds. $10 \%$ blend also shows a little increase in the engine's $B T$ up to $0.75 \%$. Beyond $10 \% B D$, there is a clear drop in $B T$ for all the range of engine speeds studied. The change in the peak value of $B T$ with $B D$ blending compared with pure diesel fuel varied as follows $+0.75 \%$ at $5 \% B D,+0.15 \%$ at $10 \% B D,-2 \%,-4 \%,-8 \%$, $-9.5 \%$ and $-14.5 \%$ for other blends respectively.

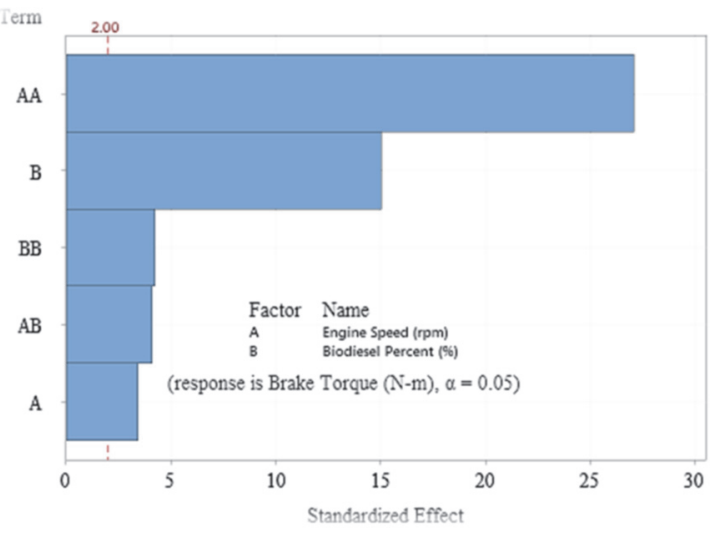

(b)

Figure 4 Variation of brake torque with biodiesel percentage at different engine speeds

At full engine speed, the drop in engine $B T$ is significant (varied between approximately $-16.5 \%$ for pure diesel to $-24 \%$ for pure biodiesel). This can be explained by referring to both fuel's properties since biodiesel is heavier and denser than diesel fuel and has greater viscosity; hence, the injected fuel will have higher momentum when penetrating through the cylinder combustion chamber compared with that of diesel fuel.

Further, due to its higher viscosity and surface tension compared with diesel fuel, the atomization process of the fuel while entering the combustion chamber will not result in breaking the fuel into fine droplets. This has a significantly adverse effect on the engine performance and the emissions due to incomplete or ineffective mixing between the fuel and air in the combustion chamber hence adversely affecting the fuel combustion process.

Several researchers studied this phenomenon and reported a loss in engine's $B T$ when using biodiesel. Cetinkaya et al. [32] showed that when using biodiesel, $B T$ will drop to about $3-5 \%$ due to the lower calorific value of biodiesel compared with diesel fuel.

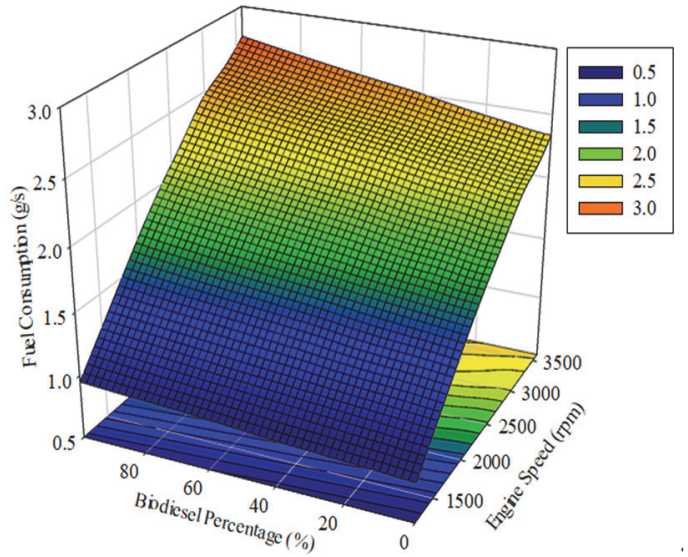

(a)
The effect of fuel properties on its injection parameters, e.g., volume/mass injected, was investigated by Tat [33]. He showed that with biodiesel, there is an increase of about $1.2-3.2 \%$ in the volume of fuel injected at the same injection pressure due to its higher viscosity and reduced backflow of fuel in the piston clearance of the injection pump during the injection process.

Usta [34] also showed an increase in the volume of fuel injected when using biodiesel as a fuel for diesel engines and attributed this to the greater viscosity of biodiesel compared with diesel fuel.

Heywood [35] derived an equation relating to the engine's power or torque to other engine parameters, e.g., volumetric efficiency $\eta_{\mathrm{vol}}$, thermal efficiency $\eta_{\mathrm{th}}$, fuel calorific value $Q_{\mathrm{cv}}$, engine size (displacement volume) $V_{\mathrm{S}}$, $H$ inlet air conditions $\rho_{\mathrm{a}, \mathrm{i}}$ and fuel-air ratio $F / A$ as shown below in Eq. (36).

$$
\text { Torque }=\frac{\eta_{\mathrm{th}} \eta_{\mathrm{vol}} V_{\mathrm{S}} Q_{\mathrm{cv}} \rho_{\mathrm{a}, \mathrm{i}}}{4 \pi}
$$

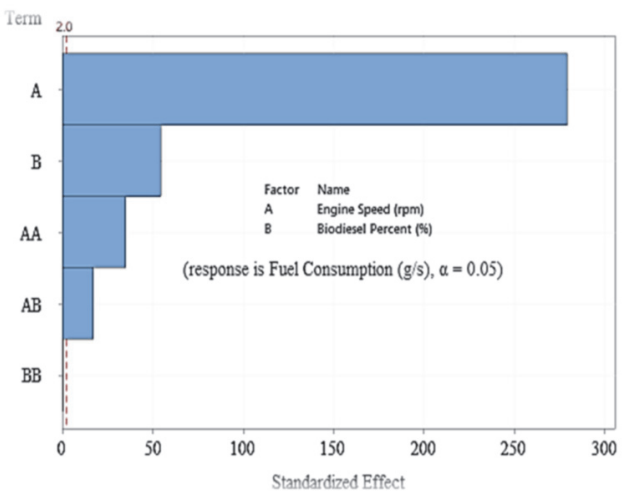

(b)

Figure $\mathbf{5}$ Variation of fuel consumption with biodiesel addition at different engine speeds 


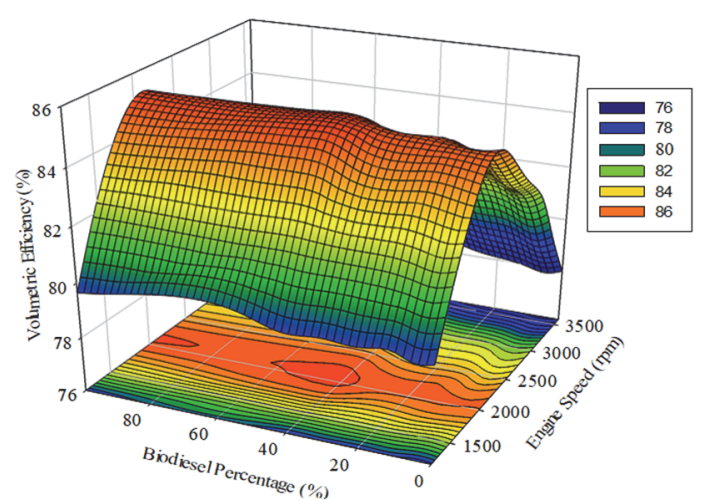

(a)

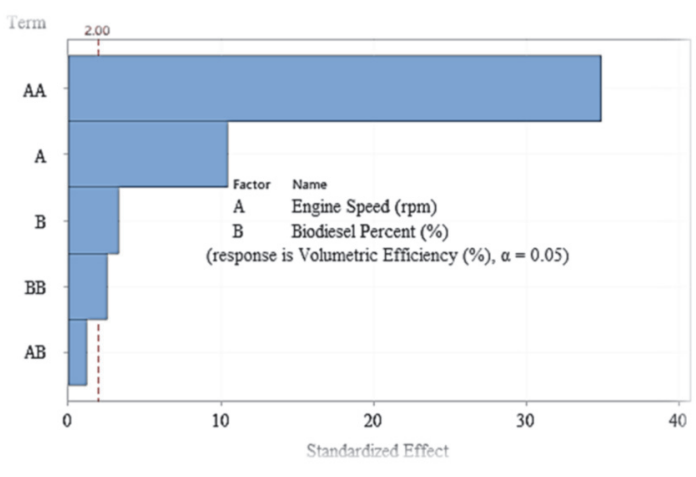

(b)

Figure 6 Variation of volumetric efficiency with biodiesel addition at different engine speeds

The above equations show a direct relationship between the engine's torque output and the fuel's calorific value. This relationship, as suggested by the equation, is a $1: 1$ ratio. However, this relation is shown in the figures, not $1: 1$; rather, the percentage loss of power exceeds that for the heating value.

The authors believe that, in real-life driving conditions, the driver always looks for the same level of driving power as with diesel fuel. Hence, when noticing that the vehicle is not responding well as it was with diesel fuel, the driver always tends to press the fuel paddle more to get the same level of performance; this results in the supply of the extra fuel that will help suppress the effect of reduced fuel's heating value. Thus the increase in fuel volume injected is reported by researchers above.

This causes the engine to consume extra fuel to compensate for the loss of energy content of the mixture and hence try to recover the loss in power (and torque). This is shown below in Fig. 5a and Fig. 5b, showing that fuel consumption is mainly affected by engine speed more than $B D$.

Lapuerta et al. [36], in his extensive review research, summarized the reasons behind the loss in engine brake torque to the following principal reasons:

A. The higher viscosity of biodiesel fuels compared with diesel, which reduces the backflow across the piston clearance of the injection pump.

B. The advanced start of combustion when using biodiesel fuels is compared with diesel due to their higher bulk modulus and sound velocity together with their higher cetane number.

C. The higher lubricity of biodiesel reduces friction loss leading to an increased brake effective power.

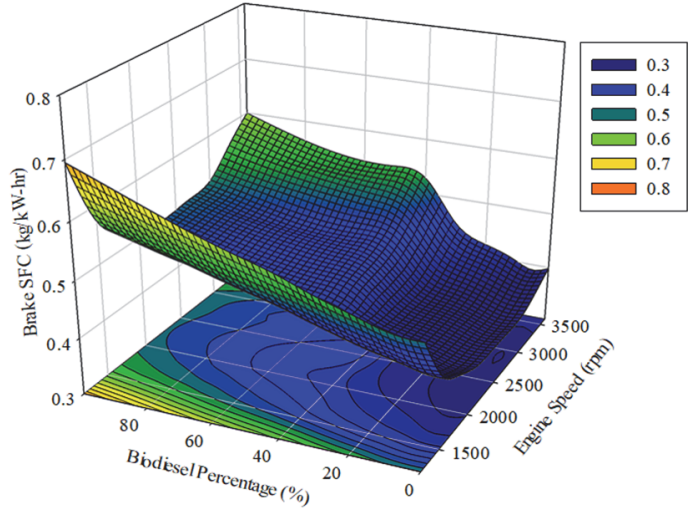

(a)

Figure 7 Variation of brake SFC with biodiesel addition at different engine speeds
Eq. (36) also suggests that volumetric efficiency can be the reason for this more significant reduction in $B T$ at full engine speed. The higher the engine speed, the shorter the duration for the engine to fill up its stroke volume, hence, an incomplete engine filling and combustion. These two factors caused the compression pressure and combustion pressure to reduce, which increased the inertia of engine parts and reduced the actual engine torque, as suggested by [30].

This effect of volumetric efficiency is also shown in Fig. 6a and Fig 6b. They clearly show that the engine speed is the crucial factor that affects engine filling compared with $B D \%$.

The above discussion supports the findings of Eq. (2) based on which Fig. 4b was drawn. It shows that the main factor that affects the engine out torque is the engine speed, which has an effect on the power of two compared with $B D$ $\%$. This can be related to the main effect of engine speed on volumetric efficiency, which is more predominant than that for $B D \%$. It also shows that there is little interaction (AB) between both variables.

\subsubsection{Brake Specific Fuel Consumption (BSFC)}

This method was also used to find the fitted model for the prediction of $B S F C$. Eq. (37) shown below has accuracy $R^{2}(A d \mathrm{j})=94 \%$.

$$
\begin{aligned}
& B S F C=0.8578-0.000397 \cdot N+0.001646 \cdot B D- \\
& -5 E-6 \cdot B D^{2}+1 E-7 \cdot N^{2}-1.5 E-6 \cdot N \cdot B D
\end{aligned}
$$

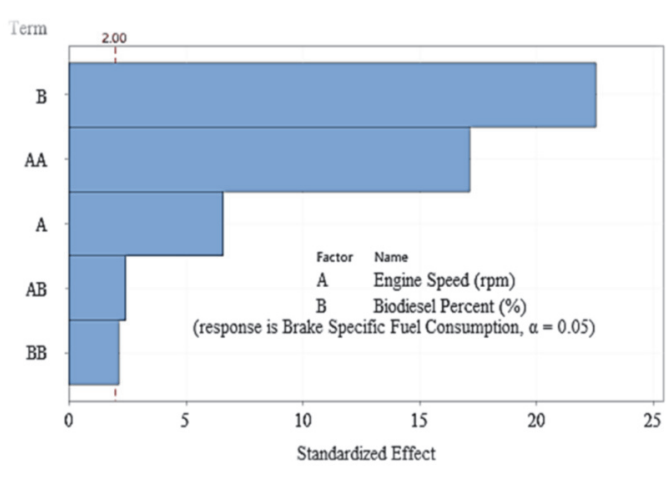

b) 
Fig. 7a clearly shows that at $5 \% B D$, there is a slight decrease in $B S F C$ from $0.2 \%$ at lower engine speeds to $2.0 \%$ at higher engine speeds. Beyond $5 \% B D$, there is a clear increase in $B S F C$ for all the range of engine speeds and $B D \%$ studied.

The change in the minimum value of $B S F C$ with $B D \%$ blending compared with pure diesel fuel varied as follows $-0.7 \%$ at $5 \% B D,+1.25 \%,+5.4 \%,+9.5 \%,+17.3 \%$ $+21.3 \%$ and $+38.6 \%$ for other blends respectively.

Based on the equation suggested by [35], BSFC can be related to thermal and volumetric efficiencies, calorific value engine size, speed, and inlet air condition as shown in the equation below:

$$
S F C=\frac{2}{\eta_{\mathrm{th}} \eta_{\mathrm{vol}} V_{\mathrm{S}} Q_{\mathrm{cv}} \rho_{\mathrm{a}, \mathrm{i}}\left(\frac{F}{A}\right)}
$$

This suggests that there should be around a $14 \%$ (which is the same as the percentage loss in heating value) increase in $S F C$ for the same load or power as diesel fuel.

Further, The United States Environmental Protection Agency (US-EPA) conducted an extensive data collection and statistical analysis of this data. It came up with the following correlation between $B S F C$ and $B D \%$ with a $95 \%$ confidence interval shown below in Eq. (39) [36]:

$$
\frac{B S F C}{B S F C_{B D}}=\mathrm{e}^{0.0008189(B D)}
$$

This equation suggests that there is a nearly linear increase in $B S F C$ with a maximum of about $9 \%$ for pure biodiesel $(B D=100 \%)$. This is also shown in our study in Fig. 5a. Since this maximum increase is lower than the loss in heating value, this result implies little improvement in the thermal efficiency with biodiesel fuel.

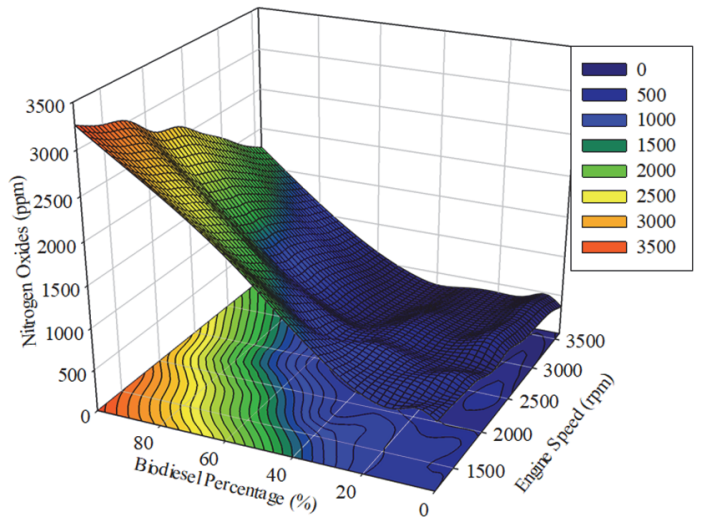

(a)
These studies support the results and findings obtained in this work. To summarize this section, we can say that at low loads, low engine speeds, the effect of biodiesel addition is favorable to the engine; however, more improvement can be achieved if engine modifications are introduced, e.g., higher pressure injection pump, reduced fuel viscosity.

Fig. 7 clearly shows that the effect of $B D \%$ exceeds that for the engine speed to power 2. This makes $B D \%$ the critical factor in determining the engine's economy. Referring to Eq. (38), $S F C$ is inversely proportional to the calorific value and thermal efficiency. Both of these factors are mainly affected by $B D \%$ than engine speed.

\subsubsection{Nitrogen Oxides}

Several emissions were tested in this study, e.g., Nitrogen Oxides, Carbon dioxide $\left(\mathrm{CO}_{2}\right)$, Particulate matter $(P M)$.

Fig. 8 shows the variation of Nitrogen Oxides emissions with biodiesel percentage. The figure clearly shows that there is an increase in Nitrogen Oxides with biodiesel.

To start with, the model proposed by the RSM is shown below in Eq. (40). The equation has an accuracy of $R^{2}(A d j)=98 \%$.

$$
\begin{aligned}
& \text { Nitrogen Oxides }=1290-0.353 N+5.99 B D+ \\
& +0.000039 N^{2}+0.2580 B D^{2}-0.005489 N \cdot B D
\end{aligned}
$$

Fig. 8a shows that there is a reduction in Nitrogen Oxides level with engine speed. The minimum reduction is about $-2.5 \%$ at lower engine speeds, and the highest is about $-50 \%$ at higher speeds. A similar trend with different values is shown for all $B D \%$. Perhaps, the higher the engine speed (as stated earlier), the less the amount of oxygen available for combustion, hence, the lower the combustion efficiency.

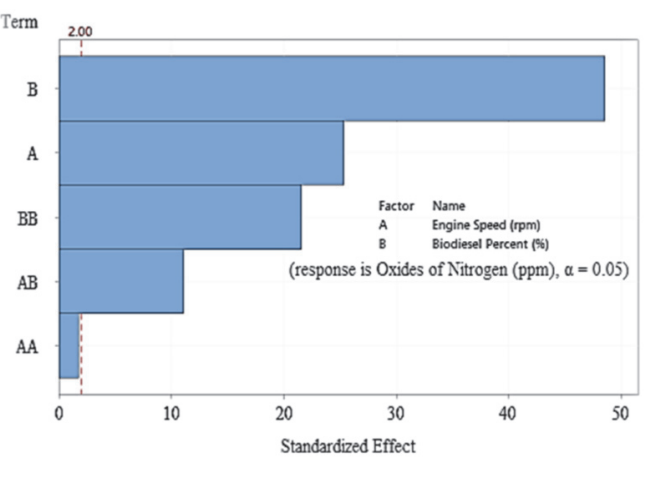

(b)

Figure 8 Variation of brake Nitrogen Oxides emissions with biodiesel addition at different engine speeds

Further, the figure clearly shows that if we compare the peak values of Nitrogen Oxides for each $B D \%$ with that for pure diesel, one finds that it comes to be $+12.5 \%$ for $5 \%$ BD till $+300 \%$ for pure biodiesel.

In the same review study presented in [36] and conducted by US-EPA laboratory experiments, the following equation, which was considered statistically significant with a confidence level of $95 \%$, was found relating the engine's Nitrogen Oxides emitted with the $B D \%$ used in the fuel:

$$
\frac{\mathrm{NOx}}{\operatorname{NOx}_{B D}}=\mathrm{e}^{0.0009794(B D)}
$$


This equation also suggests that as the percentage of $B D$ in the fuel bend increases, the Nitrogen Oxides level will also increase almost linearly with a maximum of $110 \%$.

Most researchers showed the same results, i.e., an increase in the Nitrogen Oxides level with that of the $B D$ $\%$ in the fuel blend due to the advanced combustion process caused by fuel properties as discussed above in brake torque (viscosity, density, compressibility, sound velocity).

In modern systems used for fuel injection pumps, an electronic advance in the injection pump when biodiesel is used has been suggested as an additional reason for the combustion advance and hence the increase in Nitrogen Oxides level.

Some other researchers related this increase in the Nitrogen Oxides level to the higher cetane number of biodiesel fuel as compared to diesel fuel.

Seraç et al. [37] also reported an increase in Nitrogen Oxides emissions with biodiesel fuel blends. Among the reasons given for this trend, the higher combustion temperature exceeded $1800 \mathrm{~K}$, higher iodine number, and the oxygen contents of biodiesel.

Another reason explaining the increase of Nitrogen Oxides emissions with biodiesel is the reduced soot formation due to the presence of oxygen in the fuel.

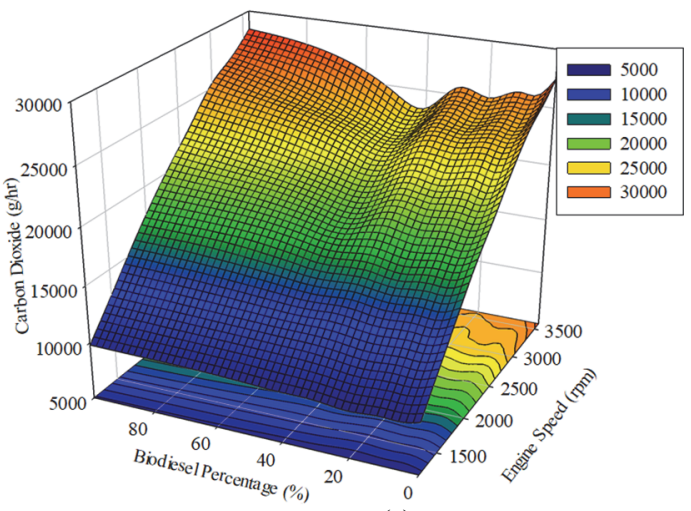

(a)
Fig. $8 \mathrm{~b}$ shows that the main factor in the increase in Nitrogen Oxides level is $B D \%$. Engine speed plays a lesser role compared with $B D \%$.

\subsubsection{Carbon Dioxide (CO2)}

The model predicted by the DOE method is given in Eq. (41) below. The model is shown to have an accuracy of $R^{2}(A d \mathrm{j})=98.62 \%$.

$$
\begin{aligned}
& \mathrm{CO}_{2}=-4489+13.650 N-58.0 B D- \\
& -0.001419 N^{2}+0.6417 B D^{2}+0.00092 N \cdot B D
\end{aligned}
$$

Fig. 9 below shows the effect of biodiesel on the carbon dioxide level. The figure shows that $5 \% B D$ in the blend produced the most significant reduction in $\mathrm{CO}_{2}$ level of up to $4 \%$. This percentage reduction diminished with the increase in biodiesel level till it reached a $4 \%$ increase in $\mathrm{CO}_{2}$ with biodiesel levels higher than $50 \%$.

Several researchers also reported an increase in $\mathrm{CO}_{2}$ levels with biodiesel addition. The presence of an Oxygen molecule in biodiesel fuel reduced the amount of stoichiometric air needed for complete combustion in the case of biodiesel.

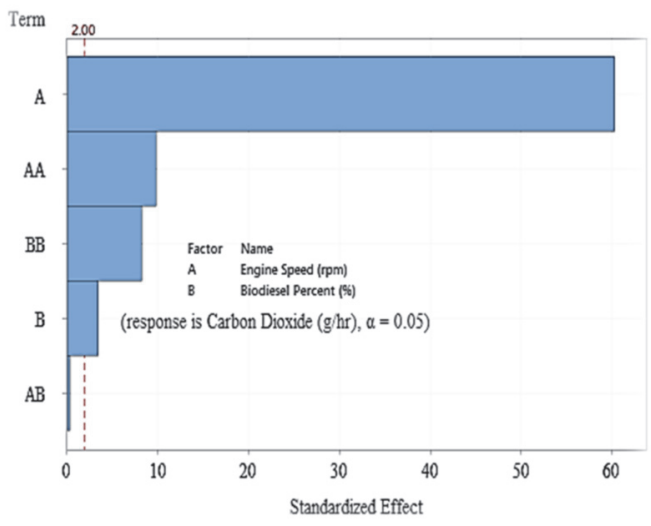

(b)

Figure 9 Variation of brake $\mathrm{CO}_{2}$ emissions with biodiesel addition at different engine speeds

This, in turn, increases the combustion possibility of the fuel-rich regions inside the combustion chamber due to the non-uniform fuel/air mixture and hence helps reduce the formation of soot. Similar results were also shown by [37].

Another reason given to explain the increase in $\mathrm{CO}_{2}$ is related to the reduced aromatics in biodiesel fuels and the absence of sulfur content, which prevents the formation of sulfate.

\subsubsection{Particulate Matter (PM)}

Finally, the model for the parameters related to the Particulate Matter $(P M)$, as given by the DOE method, is shown below in Eq. (42). The model has an accuracy of $R^{2}$ $($ Adj $)=98.61 \%$.

$$
\begin{aligned}
& P M=-4.12+0.02276 N-0.1957 B D+ \\
& +0.000001 N^{2}+0.002204 B D^{2}-0.000031 N \cdot B D
\end{aligned}
$$

As for the results of Particulate matter, this is shown in Fig. 10. As the figure suggests, there is a major reduction in $P M$ levels with biodiesel addition.

At first, the $P M$ level increased with biodiesel level up to $5 \%$, reaching an average of $7 \%$, later this increment diminished with the increase in biodiesel level till it reached about $5 \%$ with pure biodiesel. This trend was clear for all engine speeds tested.

EPA [36] showed that $P M$ could be related to $B D \%$ with $95 \%$ confidence as follows:

$\frac{\mathrm{PMx}}{\mathrm{PM}_{B D}}=\mathrm{e}^{-0.006384(B D)}$

This equation provides a maximum reduction of $P M$ emissions of close to $52 \%$ for pure biodiesel. The reasons suggested for the increase of $\mathrm{CO}_{2}$ were also suggested to explain the reduction in $P M$ levels.

To summarize this section, we conclude that the significant contribution of biodiesel is the assistance in 
completing the combustion process by supplying the cylinder with extra oxygen that is built into its structure.

Finally, one must search for any correlation or interaction between the various parameters studied. This is done using the design of the experimental approach. The response surface methodology has been proposed for this purpose. The software used for this study is Minitab.

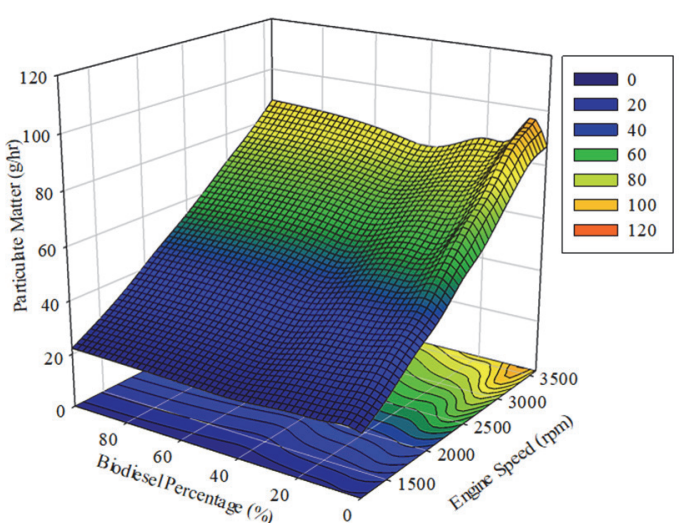

(a)

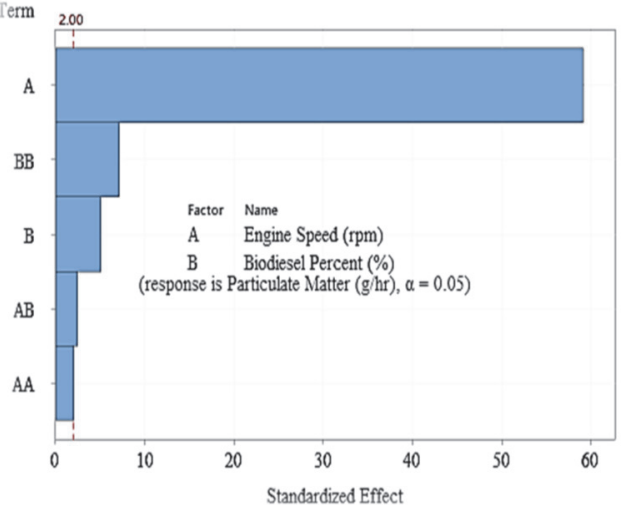

(b)

Figure 10 Variation of brake $P M$ emissions with biodiesel addition at different engine speeds

\section{CONCLUSIONS}

The effect of biodiesel blending with diesel fuel on the performance of the compression ignition engine was studied. The addition of biodiesel up to $5 \%$ to diesel fuel proved to be best from engine torque, $S F C$ point of view.

Also, Nitrogen Oxides and $\mathrm{CO}_{2}$ emissions increased as a result of complete combustion with the addition of biodiesel. Particulate matter emissions decrease significantly, reaching up to a $60 \%$ decrease from pure diesel.

From a statistical point of view, controlling the engine speed and biodiesel percentage in the fuel blend is shown to be the most significant factor. From the $S F C$ and Nitrogen Oxides point of view, biodiesel percentages are the most significant factor.

Carbon-related emissions are more affected by engine speed than with biodiesel addition.

Finally, it was found that RSM was successful in modeling the engine behavior using biodiesel-diesel fuel blends and showed good accuracy upon verification.

\section{REFERENCES}

[1] Sheet, E. A. E. (2020). Modeling of Properties and SI Engine Pollution of Associated Petroleum Gas in Iraq. Journal of Petroleum Research \& Studies (JPRS), 27(6), E1-E16. https://doi.org/10.52716/jprs.v10i2.340

[2] Yamin, J. A. A. Y. \& Sheet, E. A. E. (2020). Potential Utilization of Iraqi Associated Petroleum Gas as Fuel for SI Engines. Jordan Journal of Mechanical and Industrial Engineering (JJMIE), 14(3), 349-359.

[3] Hirkude, J. \& Belokar, V. (2020). Investigations on Performance of CI Engine with Waste Palm Oil BiodieselDiesel Blends Using Response Surface Methodology. In Advances in Energy Research, 2, 505-514. Springer, Singapore. https://doi.org/10.1007/978-981-15-2662-6_46

[4] Saravanan, S., Kaliyanasunder, R., Kumar, B. R., \& Rao, G. L. N. (2020). Effect of design parameters on performance and emissions of a $\mathrm{CI}$ engine operated with diesel-biodieselhigher alcohol blends. Renewable Energy, 148, 425-436. https://doi.org/10.1016/j.renene.2019.10.049
[5] Saxena, V., Kumar, N., \& Saxena, V. K. (2019). Multiobjective optimization of modified nanofluid fuel blends at different $\mathrm{TiO} 2$ nanoparticle concentration in diesel engine: Experimental assessment and modeling. Applied energy, 248, 330-353. https://doi.org/10.1016/j.apenergy.2019.04.091

[6] Paramasivam, B. (2020). Fuzzy prediction and RSM optimization of CI engine performance analysis: aegle marmelos non-edible seed cake pyrolysis oil as a diesel alternative. Energy Sources, Part A: Recovery, Utilization, and Environmental Effects, 1-17. https://doi.org/10.1080/15567036.2020.1773971

[7] Mahla, S. K., Safieddin Ardebili, S. M., Mostafaei, M., Dhir, A., Goga, G., \& Chauhan, B. S. (2020). Multi-objective optimization of performance and emissions characteristics of a variable compression ratio diesel engine running with biogas-diesel fuel using response surface techniques. Energy Sources, Part A: Recovery, Utilization, and Environmental Effects, 1-18. https://doi.org/10.1080/15567036.2020.1813847

[8] Sharma, A., Singh, Y., Gupta, S. K., \& Singh, N. K. (2019). Application of response surface methodology to optimize diesel engine parameters fuelled with pongamia biodiesel/diesel blends. Energy Sources, Part A: Recovery, Utilization, and Environmental Effects, 1-12. https://doi.org/10.1080/15567036.2019.1623949

[9] Billa, K. K., Sastry, G. R. K., \& Deb, M. (2020). Characterization of emission-performance paradigm of a DI$\mathrm{CI}$ engine using artificial intelligent based multi objective response surface methodology model fueled with dieselbiodiesel blends. Energy Sources, Part A: Recovery, Utilization, and Environmental Effects, 1-30. https://doi.org/10.1080/15567036.2019.1704312

[10] Banapurmath, N. R., Tewari, P. G., \& Gaitonde, V. N. (2012). Experimental investigations on performance and emission characteristics of Honge oil biodiesel (HOME) operated compression ignition engine. Renewable Energy, 48, 193-201. https://doi.org/10.1016/j.renene.2012.04.010

[11] Shirneshan, A., Almassi, M., Ghobadian, B., Borghei, A.M., \& Najafi, G. (2016). Response surface methodology (RSM) based optimization of biodiesel-diesel blends and investigation of their effects on diesel engine operating conditions and emission characteristics. Environmental Engineering \& Management Journal (EEMJ), 15(12). https://doi.org/10.30638/eemj.2016.304

[12] Yamin, J., Hdaib, I. I., Eh Sheet, E. A., \& Jehad Abu Mushref, A. (2019). RSM analysis of heat balance of direct 
injection 4-stroke diesel engine using biodiesel fuel. Biofuels, 1-11. https://doi.org/10.1080/17597269.2018.1537208

[13] Kim, H. J., Koh, D. K., Yang, J. H., Koh, S. W., Kim, Y. S., Jeong, T. Y., \& Jung, S. H. (2016). A study on the application of DOE for optimization of blending oil with non-esterified biodiesel fuel at partial engine load. Journal of the Korea Society For Power System Engineering, 20, 51-57. https://doi.org/10.9726/kspse.2018.22.1.005

[14] Ganapathy, T., Gakkhar, R. P., \& Murugesan, K. (2012). Optimisation of injection timing and operating parameters on Jatropha biodiesel engine using RSM. International Journal of Renewable Energy Technology, 3(3), 254-275. https://doi.org/10.1504/IJRET.2012.047486

[15] Kumar, B. R., Saravanan, S., Rana, D., \& Nagendran, A. (2016). Combined effect of injection timing and exhaust gas recirculation (EGR) on performance and emissions of a DI diesel engine fuelled with next-generation advanced biofueldiesel blends using response surface methodology. Energy conversion and management, 123, 470-486. https://doi.org/10.1016/j.enconman.2016.06.064

[16] Krishnamoorthi, M., Malayalamurthi, R., \& Shameer, P. M. (2018). RSM based optimization of performance and emission characteristics of DI compression ignition engine fuelled with diesel/aegle marmelos oil/diethyl ether blends at varying compression ratio, injection pressure and injection timing. Fuel, 221, 283-297. https://doi.org/10.1016/j.fuel.2018.02.070

[17] Hirkude, J. B. \& Padalkar, A. S. (2014). Performance optimization of CI engine fuelled with waste fried oil methyl ester-diesel blend using response surface methodology. Fuel, 119, 266-273. https://doi.org/10.1016/j.fuel.2013.11.039

[18] Kannan, G. R. \& Anand, R. (2012). Effect of injection pressure and injection timing on DI diesel engine fuelled with biodiesel from waste cooking oil. Biomass and bioenergy, 46, 343-352. https://doi.org/10.1016/j.biombioe.2012.08.006

[19] Yilmaz, N., Vigil, F. M., Benalil, K., Davis, S. M., \& Calva, A. (2014). Effect of biodiesel-butanol fuel blends on emissions and performance characteristics of a diesel engine. Fuel, 135, 46-50. https:// doi.org/10.1016/j.fuel.2014.06.022

[20] Mofijur, M., Masjuki, H. H., Kalam, M. A., \& Atabani, A. E. (2013). Evaluation of biodiesel blending, engine performance and emissions characteristics of Jatropha curcas methyl ester: Malaysian perspective. Energy, 55, 879-887. https://doi.org/10.1016/j.energy.2013.02.059

[21] How, H. G., Masjuki, H. H., Kalam, M. A., \& Teoh, Y. H. (2014). An investigation of the engine performance, emissions and combustion characteristics of coconut biodiesel in a high-pressure common-rail diesel engine. Energy, 69, 749-759. https://doi.org/10.1016/j.energy.2014.03.070

[22] Dwivedi, G., Jain, S., \& Sharma, M. P. (2011). Impact analysis of biodiesel on engine performance-A review. Renewable and Sustainable Energy Reviews, 15(9), 46334641. https://doi.org/10.1016/j.rser.2011.07.089

[23] Abu Meshref, A. J. (2012). Mapping Of Direct Injection 4Stroke Diesel Engine Performance Using Biodiesel Fuel. A Master's thesis was submitted in partial fulfillment of the Requirements for the Master's Degree of Science in Mechanical Engineering, The University of Jordan.

[24] Kuleshov, A. S. (2005). Model for predicting air-fuel mixing, combustion and emissions in DI diesel engines over whole operating range (No. 2005-01-2119). SAE Technical Paper. https://doi.org/10.4271/2005-01-2119

[25] Kuleshov, A. S. (2006). Use of multi-zone DI diesel spray combustion model for simulation and optimization of performance and emissions of engines with multiple injection (No. 2006-01-1385). SAE Technical Paper. https://doi.org/10.4271/2006-01-1385
[26] Woschni, G. (1967). A universally applicable equation for the instantaneous heat transfer coefficient in the internal combustion engine (No. 670931). SAE Technical paper. https://doi.org/10.4271/670931

[27] Al-Dawody, M. F. \& Bhatti, S. K. (2013). Optimization strategies to reduce the biodiesel Nitrogen Oxides effect in diesel engine with experimental verification. Energy conversion and management, 68, 96-104. https://doi.org/10.1016/j.enconman.2012.12.025

[28] Alkidas, A. C. (1984). Relationships between smoke measurements and particulate measurements. No. 840412 . SAE Technical Paper. https://doi.org/10.4271/840412

[29] Heydari-Maleney, K., Taghizadeh-Alisaraei, A., Ghobadian, B., \& Abbaszadeh-Mayvan, A. (2017) Analyzing and evaluation of carbon nanotubes additives to diesohol-B2 fuels on performance and emission of diesel engines. Fuel, 196, 110-123. https://doi.org/10.1016/j.fuel.2017.01.091

[30] Al-Hamamre, Z. \& Yamin, J. (2014). Parametric study of the alkali catalyzed transesterification of waste frying oil for Biodiesel production. Energy Conversion and Management, 79, 246-254. https://doi.org/10.1016/j.enconman.2013.12.027

[31] Montgomery, Douglas C. (2017). Design and analysis of experiments. John wiley \& sons.

[32] Cetinkaya, M., Ulusoy, Y., Tekìn, Y., \& Karaosmanoğlu, F. (2005). Engine and winter road test performances of used cooking oil originated biodiesel. Energy Conversion and Management, 46(7-8), 1279-1291. https://doi.org/10.1016/j.enconman.2004.06.022

[33] Tat, M. E. (2003). Investigation of oxides of nitrogen emissions from biodiesel-fueled engines. $\mathrm{PhD}$ thesis, Iowa State University. Available on line: http://www3.me.iastate.edu/biodiesel/Technical\%20Papers/ Dissertation_link.htm.

[34] Usta, N. (2005). An experimental study on performance and exhaust emissions of a diesel engine fuelled with tobacco seed oil methyl ester. Energy Conversion and Management, 46(15-16), $2373-2386$ https://doi.org/10.1016/j.enconman.2004.12.002

[35] Heywood, J. B. (1988). Combustion engine fundamentals. New York, McGrawHill

[36] Lapuerta, M., Armas, O. and Rodriguez-Fernandez, J. (2008). Effect of biodiesel fuels on diesel engine emissions. Progress in energy and combustion science, 34(2), 198-223. https://doi.org/10.1016/j.pecs.2007.07.001

[37] Seraç, M. R., Aydın, S., Yılmaz, A., \& Şevik, S. (2020). Evaluation of comparative combustion, performance, and emission of soybean-based alternative biodiesel fuel blends in a CI engine. Renewable Energy, 148, 1065-1073. https://doi.org/10.1016/j.renene.2019.10.090

\section{Contact information:}

Ismail I. HDAIB

Faculty of Engineering, Renewable Energy Engineering, Isra

University,

Amman 11622, Jordan

E-mail: ismail.hdaib@iu.edu.jo

\section{Jehad A. YAMIN}

(Corresponding author)

School of Engineering, Mechanical Engineering

Department, The University of Jordan,

Amman 11942, Jordan

E-mail: yamin@ju.edu.jo 


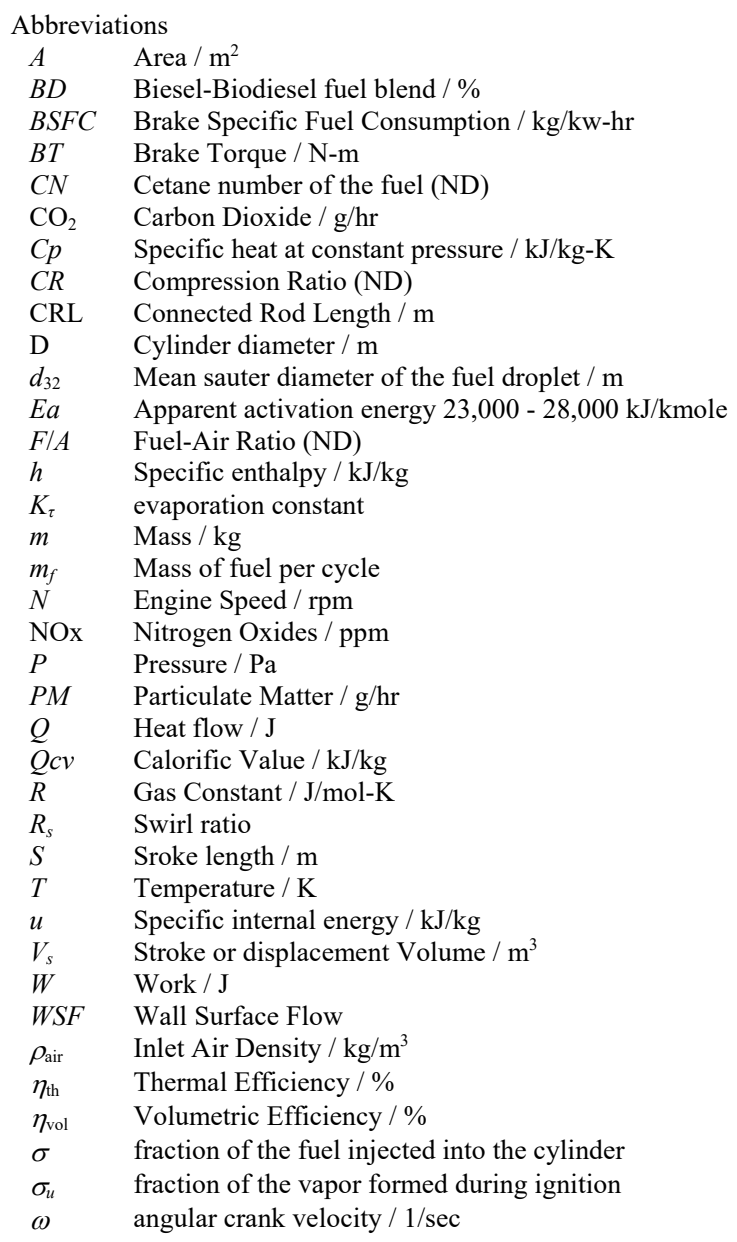

